\title{
6 \\ THE REVITALIZATION OF MASS PRODUCTION IN THE COMPUTER AGE
}

\author{
Benjamin Coriat
}

\section{INTRODUCTION}

The starting point of this chapter is common to many people working in the field of industrial economics. Most observers agree on the two following basic propositions:

1 as a response to decreasing productivity gains and the new structural instability of the market, the present moment is marked by a set of interrelated organizational and technological innovations at the level of the firm, and

2 this set of innovations has given rise to a new technological trajectory, where the search for more flexible arrangements is the key distinctive feature; along with this new trajectory new principles of economic efficiency are emerging and spreading throughout the whole economy.

From this common starting point, different interpretations of what is happening to the old classical Fordism are emerging. A number of different theses have been sustained. One can identify two basic, opposed, arguments.

1 The long waves hypothesis (Freeman 1984, Mensch 1978): after a more or less difficult and long transition, the economy will recover and enter onto a new path of economic growth. According to this view, attention must be concentrated on the process of transition. Efficient R\&D and technological policy is required, along with a strengthening of education and training systems.

2 The flexible specialization hypothesis (Piore and Sabel 1984): the new technological trajectory means the end of the whole Fordist structure and emergence of a new form of industrial organization where flexible small and medium-sized firms play the dominant role, since they have a greater capacity to react to the new structural instability of the markets.

Many different variants and submodels of these two basic approaches have also been devised.

Along with Robert Boyer, in an earlier essay I attempted to trace a vision of the process (Boyer and Coriat 1989). In brief our thesis is that as regards the norms and conditions of production, the new technological trajectory is much more a revitalization of mass production principles than an alternative and new way of producing goods. The paper then develops the thesis that the arrangements around the "wage relation nexus" (rapport salarial) will finally decide the definitive configurations of the general 
structure of post-Fordism.

In this chapter I would like to elaborate this first vision. To do so, I have chosen to begin with a short but general reconsideration of the elementary principles of efficiency embodied in the typical Fordist "engine of growth." The second part of the chapter is then dedicated to a preliminary attempt to formalize the main changes experimented with during the present days by the classical principles of efficiency.

Furthermore, I introduce some new analytical tools to approach the different components of the so-called "post-Fordism." My starting point is that the transition from Fordism to post-Fordism, in fact, means a transition in the principles of economic efficiency of the whole structure of modern capitalism. It is obvious that during the last twenty years a set of very deep changes has taken place. These changes are specific to each level of the capitalist structure and largely interdependent. So while it is easy to localize and describe the different "local" changes, it is more difficult to obtain a clear and organized representation of the new articulations between the different separate levels. It is, however, the purpose of this chapter to give a first characterization of the specific local changes and of the new general structure which is emerging.

\section{FORDISM AND ITS PRINCIPLES RECONSIDERED: SOURCES AND ORIGINS OF ITS EFFICIENCY}

The "theoretical skeleton" of Fordism consists of a series of coherent and interrelated norms as far as the different levels of analysis of the capitalist dynamics (productivity, production, consumption) are concerned.

In the following my purpose is to give a theoretical characterization of the implicit dynamics of the Fordist productive structure and organization. I begin with the simplest level (origins of the productivity gains in the labor process) and proceed by trying to integrate the other more abstract levels (norms of production, of competition, industrial organization, etc.). The point here is to "open up" the fantastic engine of growth of the classic Fordist mode of accumulation, to extract and make visible the different sources and natures of its productivity gains.

\section{The basic principles of the classic Fordist "engine of growth"}

We can pose the following "stylized facts" concerning the sources of efficiency of the Fordist model.

- At the level of the labor process productivity gains (or if one prefers, the "norms of productivity") are based on a simple and rough parameter: division of labor+mechanization and rigid automation. The type of division of labor (coherent with mechanization and rigid automation) is itself sustained by the old "classical" idea that maximum output is closely related to the maximization of the efficiency of the individual worker. Here the idea is that important "learning" gains are based on fragmentation and repetition. This is the reason why we have chosen to term the implicit principle of efficiency at work in this paradigm as (the pursuing of) a "Smith effect," in reference to A.Smith, who certainly placed maximum emphasis on this 
particular concept of efficiency. Taylor and Ford systematically exploited this concept and principle of economic efficiency through scientific management and the introduction of the assembly line. In this sense, they contributed to the hegemony of the basic paradigm, first introduced by Smith and the classical economists.

- Consistent with this vision of the sources of productivity gains, the specific norms of production of the Fordist mode of accumulation were based on an attempt to capture in a systematic way the benefits of economies of scale through long series of standardized products. A "Young effect" is thus one of the characteristics of the origins of the productivity gains pursued by the classical Fordist structure. The Fordist factory is typically a big factory and vertical and/or horizontal integration is the natural complement of this organizational structure of the economy. In my view, this is the reason why the transaction cost analysis pioneered by Coase and reshaped by Williamson has been mainly used until very recently to justify the growing process of internalization of activities in the firm. The benefits of what we can call the "internalization effect" were thus explicitly evoked to explain and justify the continuous process of concentration experienced by the firm during the classical period of hegemony of the Fordist mode of accumulation.

- The norms of competition reflect this basic organization: the competition between firms basically involves a long series of standardized products. In the rivalry between firms, the capacity to offer products at lower costs is more important than any other attribute of the products. So clearly we are in a world dominated by oligopolies, and the competitive game is played under the specific rules of oligopolistic competition. Barriers to entry are formed by the economies of scale required to maintain a competitive position in a world of growing firms and markets. Certainly it was Bain (1954 and 1959) who painted the most precise picture of the universe crated by the progressive hegemony of Fordism.

- A well-defined pattern of industrial organization emerges from these characteristics: basically the center of power lies in the hands of the big enterprise (the so-called "monopoly capitalism"); around it a series of dominated small or medium-sized enterprises are subjected to subcontracting procedures. They are thus obliged to assume many of the inherent risks of market changes. Among these firms some are "captured" since the big enterprise tries to reap the benefits of vertical (or horizontal) integration through consolidated links with some of its suppliers.

- Last but not least, if we consider the whole macro-model emerging from this set of norms, the huge productivity gains extracted from these arrangements made it possible to transfer a sufficient amount of them to the wages to be able to capture the benefits of mass consumption along with mass production.

To summarize, one can present the specific Fordist engine of growth as a combination of division of labor and mechanization (Smith effect)+ economies of scale (Young effect) +vertical integration in a world dominated by competition through long series and oligopolistic markets.

\section{The disintegration of the Fordist engine of growth}

Continuing with stylized facts, we can advance the notion that the disintegration of the 
efficiency of the Fordist engine of growth has two basic and largely interrelated origins:

- The first one is the so-called "productivity slowdown" which begins (in the US) at the end of the 1960s, and spreads through the whole economy during the 1970s. Many different explanations were given for this crucial phenomenon (see, for instance, the sophisticated studies of The Brooking Papers dedicated to this point). Obviously there is no unique and simple explanation. It seems, however, that one of the important causes of this productivity slowdown is the end of the potential benefits embodied into the old Smithian paradigm: the trajectory "division of labor+mechanization" reached obvious technical and social limits (see Coriat 1982 or in the radical American tradition, Bowles, Gordon and Gintis 1983).

- These limits appeared to be stronger in the 1970 s, since markets faced dramatic changes, meaning dramatic modifications in the norms of competition. The individual firm was thus faced with a completely new environment. Markets became unstable and largely unpredictable, and product life cycles experienced dramatic decreases. In such conditions new possibilities were opened up and the whole classical Fordist structure - under dramatic pressure-entered into a process of continuing change which imposed an adaptation to the new reality.

\section{THE PRESENT CHANGES: PATHWAYS TOWARDS POST-FORDISM}

In practice the adaptation began at the workshop level. A set of technological and organizational innovations took place and began to modify the traditional way of producing goods in order to generate new sources of productivity gains.

\section{The rise of flexibility and the emergence of new "post-Fordist" principles of efficiency}

If we concentrate on the enterprise, the content of the so-called new technological trajectory is basically twofold, since the interrelated fields concerned are technology and organization. Further specification is necessary to understand the full implications of the theoretical issues at stake.

Concerning technology the main novelty is the rise of flexible and programmable automation, starting with individual tools (robots, numerically controlled machine tools) and spreading itself through a series of new integrated systems (FMS, CAD/CAM). The benefits given by these new tools and arrangements can be summarized as follows:

\section{Process-flexibility: the new automation makes it possible to use facilities at full} capacity even under uncertain demand; by producing more than one product in the same basic installation the full capacity installed can be worked on, which is impossible in a "rigid" factory. In the latter, any shortage in demand is necessarily followed by certain percentage of under-utilization of capacity, with obvious negative effects on profitability. This advantage given by new flexible automation is termed "Marshall effect" (see Figure 6.1). 


\begin{tabular}{|c|c|c|c|}
\hline Technical Basis & $\begin{array}{c}\text { Origh of the } \\
\text { Productivity Gains }\end{array}$ & Empirical Concepts & $\begin{array}{l}\text { Theoretical Final } \\
\text { Concepts Designation }\end{array}$ \\
\hline $\begin{array}{l}\text { (1) Procoss } \\
\text { Floxibility } \\
\text { and }\end{array}$ & $\begin{array}{l}\text { Now Balance } \\
\text { Between Fixed } \\
\text { and Variablo Costs }\end{array}$ & $\begin{array}{l}\text { Decrease Marginal } \\
\text { Costs by Using the } \\
\text { Full Capacty } \\
\text { Instalied }\end{array}$ & $\begin{array}{l}\text { Stasce } \\
\text { Econorpy of } \\
\text { Sealo }\end{array}$ \\
\hline (2) Product & $\begin{array}{l}\text { Joint Production } \\
\text { with variabion } \\
\text { composison of tho } \\
\text { Ouputs }\end{array}$ & $\begin{array}{l}\text { Decrease in } \\
\text { Average Costs }\end{array}$ & Eoonomy of \\
\hline
\end{tabular}

Figure 6.1 Economics of multiproduction from the Marshall effect to the Baumol effect

2 Product-flexibility: this is another dimension of the same phenomenon. It basically concerns the benefits of the economies of scope associated with flexible technologies. I refer to them as the benefits of the "Baumol effect" in reference to the seminal contribution made to their understanding by Baumol, Panzar and Willig (1982) (see Figure 6.1).

3 Dynamically (see Figure 6.2): the cumulative investment in flexible 


\section{A. Rigid Plants: A Process of Cumulative Gaps}

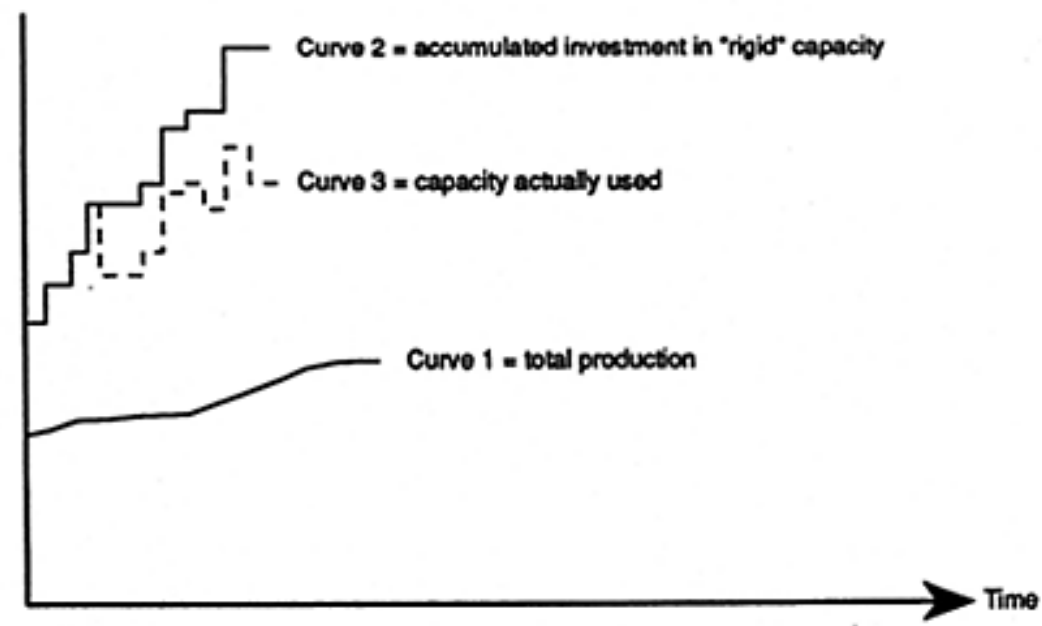

Comments:

- The hypothesis of a slow growth rato of demand is represented by Curve 1.

- The impact on total capacity investment is represented by Curvo 2.

- The gap botwoon Curvo 1 and 2 rolios on tho tact that the different "models" yiold sales quantitios diflerent from the actual production.

- Curve 3 is a representation of actual production.

- The gap botwoon Curves 3 and 2 is a "graphical" expression of under-utilization.

\section{B. Flexible Plants: A Convergent Process}

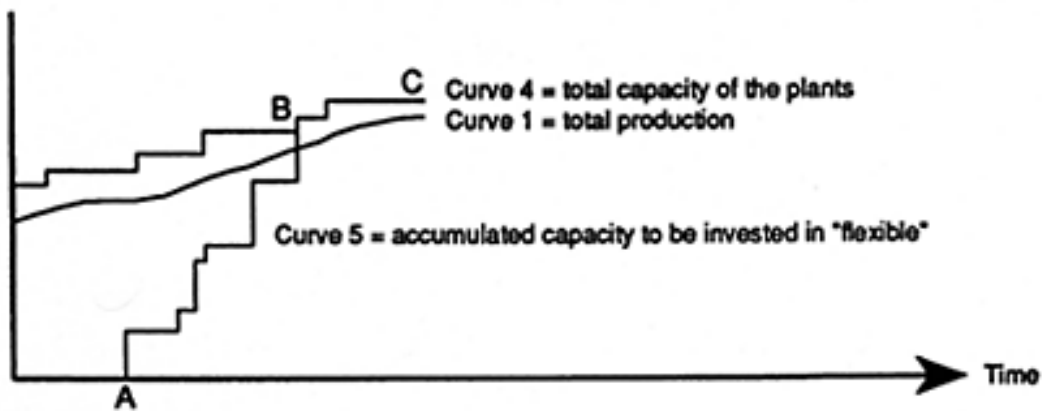

Comments:

- Curve 1 (total production) is the same as in the former case, but;

- Capacity instalied to produce the first "model ( $A$ in the figure) can be used (at low additional $\cos 1)$ to produce the new models (B and C) as the form $A$ disappears from the market.

- It is the case that the Curves 4 and 5 (equivalent to Curves 2 and 1) are now basically convergent.

Figure 6.2 Flexible technology: long-term impact of firm capacity strategy 
technologies permits optimization of the total amount of capital invested to produce the different products sold on the market at different stages in their respective lifecycles.

Summarizing the theoretical benefits associated with the new electronics-based technologies, we can say that flexible automation gives rise to two fundamentally new phenomena:

a) a "Marshall effect," based on the fact that the capabilities can be used at full capacity even in a changing environment,

b) a "Baumol effect," which refers to the fact that economies of scope can be secured in an ordinary way, using the same basic (flexible) lines of production to produce a set of differentiated goods according to the market needs.

It is essential to note that these new tools and integrated automatic systems are emerging along with new organizational concepts and procedures. It is increasingly clear that the organizational revolution is probably more crucial than the technical one. The growing evidence concerning this organizational revolution is that a new Japanese school is taking the place of the old classical American school. In theoretical terms, the organizational revolution (at the workshop level) is the combination of new principles and techniques involving two dimensions of the classical production management methods: at the level of logistics and of production planning.

By logistics, we refer to the way the flow of semifinished products (raw materials, components, energy, etc.) is coordinated with production operations. One can say that the essence of this new conception consists in a new optimization between elementary circulating and operating times, allowing a high level of economy in lead times.

At the level of planning, either through MRP (Material Requirement Planning) or through Just-in-Time, benefits of different types and origins are gained. Techniques such as Just-in-Time, Kan-Ban, and Quality Circles are the elements of a new paradigm in the field of production management. A set of original sources of productivity gains is thus explored in the new, different layouts and "orgwares" conceived and installed at enterprise level. Figure 6.3 outlines these new developments in detail. (For a detailed analysis of the Japanese school on production management, see Coriat 1991.)

As a consequence of these changes, the classic Fordist structure and organization of production face dramatic shifts. To sum up the situation, the transition from Fordism to post-Fordism can be read as a move toward new principles of efficiency. Fordism is establishing itself on new micro-foundations.

\section{"Post-Fordist" principles of efficiency: the new micro-foundations of mass production}

Following the same methodology used in the previous section we can sketch the main theoretical changes at different levels of the old classical structure; 

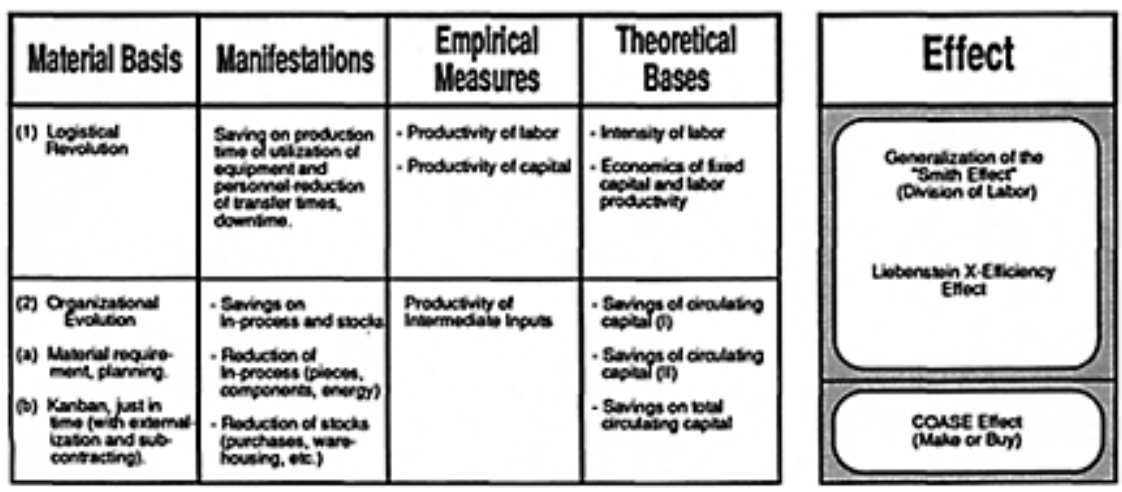

Figure 6.3 Economies of organization: content and nature

1 At the level of the division of labor: the transition is from the old and rather rough "Smith effect" to a new paradigm based on the idea that the maximization of the output does not rely on the performance of the individual worker, but is primarily related to the optimization of operations and processes in a world where the adaptation to unpredictable markets is the new rule of the game (see Ohno 1989 and Shingo 1983). In such conditions, a revolution is underway in the organization of the assembly line and the process of balancing jobs along the production process. In this field, we are passing from allocated time procedures to organization in sharing times, or in other words from rigid standards to flexible and modulable ones (see Figure 6.4). This revolution based on new layouts (linearization and " $U$ " form of productive arrangements) was achieved by Ohno (1989) inside Toyota. In conceptual categories these new methods and procedures belong to the "organizational efficiency" principle first emphasized by Leibenstein (1966) in his seminal essay on "X" Efficiency theory. This is the reason why this concept of productivity may be characterized as the passage from the "Smith effect" to the "Leibenstein effect".

2 At the level of the production process: to face the new characteristics of the market (uncertainty, unpredictability) and the changing behavior of the consumer, the transition is from specialized and dedicated layouts to new patterns of production organization, based on economies of scope. The objective here is to pass from the benefits of the "Young effects" to the advantages of the "Baumol effects" (see Figure 6.3). Combining the potential resources of the new organizational concepts (Ohno and the Japanese school) with the new programmable technological tools the productive arrangements are now able to mix the advantages of long series with those of differentiated products in small and medium-sized batches.

3 At the level of the industry: a new organization supported by original configurations is emerging. The benefits of vertical integration (i.e. internalization or quasiinternalization through hierarchical subcontracting systems) are no longer-if they ever were - a panacea. Horizontal de-concentration, quasi-disintegration in new subcontracting systems, based on long-term contracts are taking the place of the classical Fordist industrial arrangements. Briefly, we can say that in the place of the 
Bain principle of efficiency, an Aoki principle (to refer to his vertical versus horizontal anatomy of the respective "A" and "J" forms assumed by the firm) may be found (Aoki 1986).

Thus, some common basic principles of any type of post-Fordist productive structure can be defined. As for the theoretical skeleton of the post-Fordist regime of accumulation at the level of the industrial structure as a whole, the norms of production are moving from standardized products to mass-produced but modulable and differentiated ones, while the norms of 
A: The basic lay-out of the "U" form orgenization

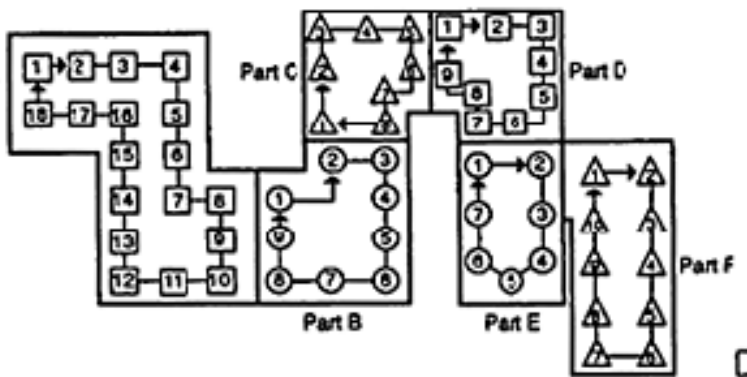

- Six work stations

- Inside each work station successivo lasks are delimited (18 tasks in

workstation $\Lambda, 9$ in $B$,....

- These tasks are performos every month by variable numbers ol workars (oorlorming a changing number of tasks)

\section{B: Work standards in January}

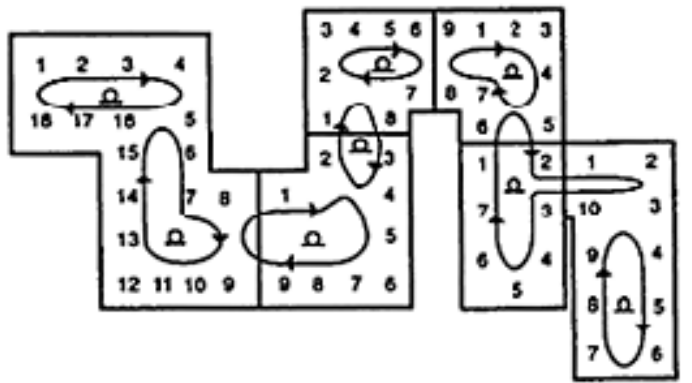

$\square \mathrm{O} \triangle$ nactines

tomo - 1 min per unis number of wortors = 8 perrons $\rightarrow$ work rous of a ach wakner

\section{C: Work standards In February}

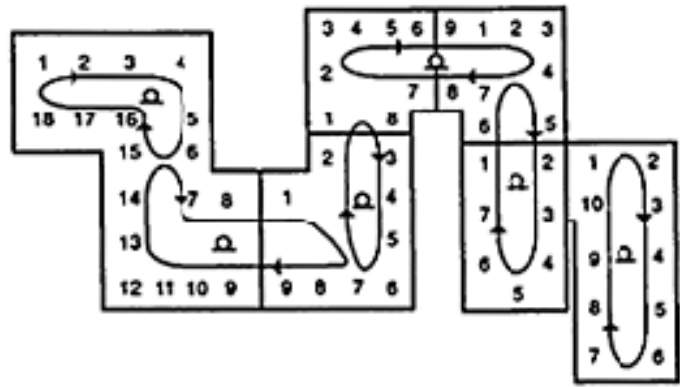

C:olo timo - 1,2 min por unit number of woteors a 6 porcons

\section{Comments:}

$\rightarrow$ work rovis of each worker

It wo compare the work organization in January and Fobruary, overything dffers. Ihe number of workers employed from (8 to 6), tho gycle tirro (irom 1 tio 1,2 ) and tho conient of the work standads aftributod to each worket.

This illustrates what can be called the peinciple of organizztion basec on "Flexide Work Standard "Of basod on "Sharod Time" 10 strictly-dolinod tasks attribured to oxch wriker (as oxposod to the old Smithian paradigm).

Figure 6.4 The Japanese revolution in product management: linearization and flexible work standards

Source: Adapted from Monden (1983) 
competition are passing from high-volume, low-priced goods to batched and differentiated ones. Here, elements of monopolistic competition (in Chamberlinian style) are penetrating the classical oligopolistic forms of rivalry between firms.

How all these new principles can be articulated in a macroeconomic model of accumulation remains a question to be answered. Many different combinations are possible, under different hypotheses of market configurations, product life cycles and so on.

\section{NEW POST-FORDIST CONFIGURATIONS}

Two basic configurations (each one including different variants) appear to be emerging to structure the productive process. Following Piore and Sabel (1984) on the one hand, and B.Klein (1986) on the other, these two principles may be characterized as follows.

\section{The flexible specialization principle and its limits}

It is not necessary here to insist on the role played in the scientific community (and far beyond) by the very stimulating book published by Piore and Sabel presenting their flexible specialization hypothesis as a possible root for "prosperity."

Since many works have been dedicated to exploring the different implications and meanings of the hypothesis, it seems better to concentrate on what we have learned during the last five or six years, concerning the way the universal need for (more) flexibility has been assumed in different contexts and situations. The following propositions are a preliminary summary of the evidence on both theoretical and empirical levels.

First, it seems clear that flexibility introduced at the level of the individual firm (either through organizational arrangements or through technology) is the basis of a specific competitive advantage. Using the resources of what we have called the "Baumol principle" and exploring in a systematic way the potentialities of economies of scope, the small or medium-sized firm, operating in unstable and changing markets, may be more efficient than the large, rigid one. The theoretical and empirical problem here is that of the limits of the strategy of economies of scope with regard to that of economies of scale (see below for a tratment of this crucial question). It is clear that in certain circumstances a strategy based on systematic efforts to secure the benefits offered by the economies of scope can be successful. (See Figure 6.5, where these kinds of successful strategies are illustrated.)

Second, it is a well-established fact that-here again, under certain market conditions and product life cycles - organized nerworks of small and flexible enterprises are able to compete even on mass production markets with the big classical Fordist factory. Many different forms of "industrial districts" 


\section{Flexible Specialization - Building a competitive advantage on Economies of Scope}

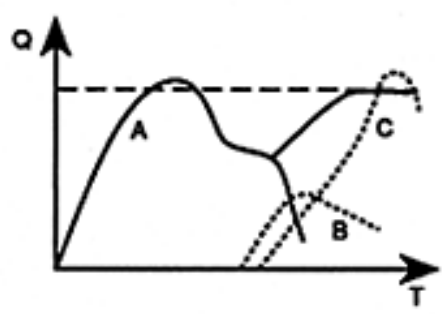

Pasaive Difforentlation

A,B.C are three diflerentiated products belonging to the same basic family.

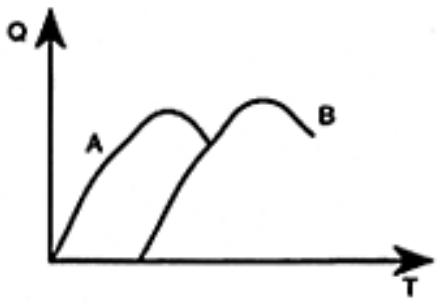

Active Diflerentiation

When the firm taces a break down of the demand lor the product A, it introduces a new product $B$. This strategy of "pormanort innovason" is efticient in markets dominated by products with short life cyclos.

\section{Dynamic Flexlbillty - Combining Economies of Scale and Economies of Scope}

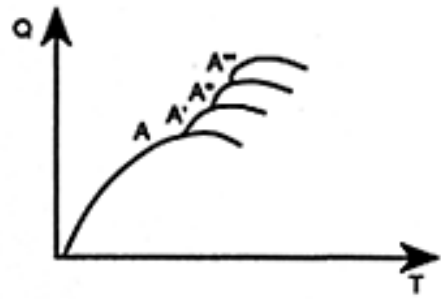

Differentiation by Syatematic Dematuration "policy

The firm extends the Flo cycle of product Aby systematic dematuration policy, introducing A: $A^{*}$ and $A^{-}$now characteristics into the product A. Thus, through ditierentiation, the firm maintains the benelits of economies of scale.

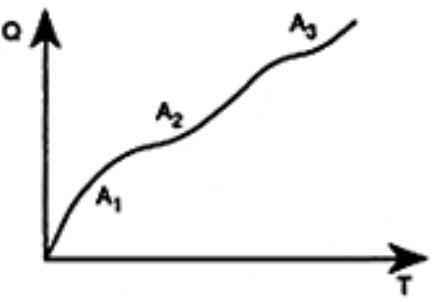

\section{Ditterentlation by Product Development}

When the product $A_{1}$ reaches the Imit in its peneiration into the market, a second generation of the same product $\left(A_{2}\right)$ is introduced by manket innovation into the makket.

Figure 6.5 Technical flexibility and product life cycles: four basic strategies

have proved their capacity to maintain an advantage even in very competitive environments (see for instance the papers published by the Italian school on industrial districts, in Maruani, Reynaud, and Romani 1989).

Nonetheless there are limits and conditions of validity of these competitive advantages. Two sets of basic conditions are required: 
1 The first conditions have to do with the products: the advantages of "flexible specialization" lie solely in manufacturing. The products must be "simple," that is to say at a stage of advanced "maturity" in their life cycle. The product may not include high conception and R\&D costs: if the barriers to entry (based on high research costs and investment) are very high, the benefits gained at the level of manufacturing would not be able to cover the costs of continuing $\mathrm{R} \& \mathrm{D}$ and product improvement. This is the reason why, if we consider the products made in the industrial districts we find basically simple and mature products such as textiles, clothing, shoes, and so on. When the product embodies innovations, the innovation is "incremental" (as opposed to "major"), and creates a temporary "niche," since followers can easily imitate the first innovators. The case of the industrial district producing numerically controlled machine tools (analyzed by Capecchi and others) does not invalidate this view. The network of small flexible firms basically consists of subcontracting firms in the sense that the research on numerical techniques and procedures is carried out in the laboratories financed by big corporations.

2 The second — and closely related — set of conditions are related to market characteristics: the market, for optimum efficiency of the flexible specialization strategy, must be a segmented one. Thus many different niches can be occupied by small firms operating in distinctive markets. The Italian School-in its best workinsists on the fact that an efficient flexible specialization strategy requires segmented markets and/or rapid changes in consumer behavior.

If these conditions are missing, then large enterprises using the opportunities offered by the new organizational arrangements are certainly in a better position to face market needs, even if small and medium-sized enterprises are much more flexible. In this case, the flexible specialization principle leaves the field open to a strategy based on dynamic flexibility.

\section{Combining the benefits of economies of scale and of scope: the principle of dynamic flexibility}

To my knowledge the notion of "dynamic flexibility" was first introduced into the scientific community by B.Klein. Describing the policy followed by certain Japanese firms, he writes:

As contrasted with static flexibility, dynamic flexibility is not concerned with producing more than one product (e.g., cars and light trucks) on a single production line - although the Japanese do this too. Rather, it is concerned with designing production lines in a way that they can quickly evolve in response to changes in either the product or production technology. In other words the central preoccupation is to get ideas into action quickly. The main purpose of dynamic flexibility, however, is to make rapid changes in production technology for the purpose of lowering costs and thereby improving productivity.

(Klein 1986)

Following this characterization Cohen and Zysman (1987) insisted on the importance of 
this principle for any policy designed to revitalize the classic Fordist industrial structure. In a recent work, I have tried to elaborate further on the basis of this idea, and give a conceptual content to the principle of dynamic flexibility as opposed to the principle of flexible specialization (Coriat 1990). Thus dynamic flexibility is defined as being based on an "iterative" process of continuous changes affecting both process and product innovations. More precisely a strategy of dynamic flexibility is followed when the productive arrangements are conceived and managed in such a way that they make it possible to modify the process (at low or zero delay and cost) according to the changes introduced into the products. An alternative solution is to modify the product to benefit from the innovations introduced at production line level. In other words, dynamic flexibility is a strategy designed to reap the reciprocal benefits of product and process innovations. Here the concept of flexible and modulable work standards conceived by Ohno is crucial. More generally a completely new model of work organization, based on strong and continuous investment in human resources, is required here. Flexibility, in this case, is based on the skills of workers to whom broad capabilities to respond to changing circumstances are given.

The main advantage of such a strategy can be shown if we consider its effect on the long-term learning curve. Here one may remember (following the work on the subject by Albernathy 1978, Albernathy and Wayne 1985) that in the long run, the learning curve is not continuous. At every important change introduced by the enterprise (concerning either the product or the process) the learning curve experiences upward movements, since the new element introduced destroys the "know-how" and the "experience" accumulated at the preceding stages of the product-process configuration. The strategy of dynamic flexibility can thus be understood as centrally designed to "smooth" these upward movements, and to maintain a continuous upward orientation of the learning curve, even when important changes are introduced. Thus dynamic flexibility supports cumulative gains of efficiency (see Figure 6.6). In a period characterized by an acceleration of this kind (affecting products and/or the processes), it is easy to imagine that this strategy can play a very important role in the competitive game. 
A. The case of the Model "T"

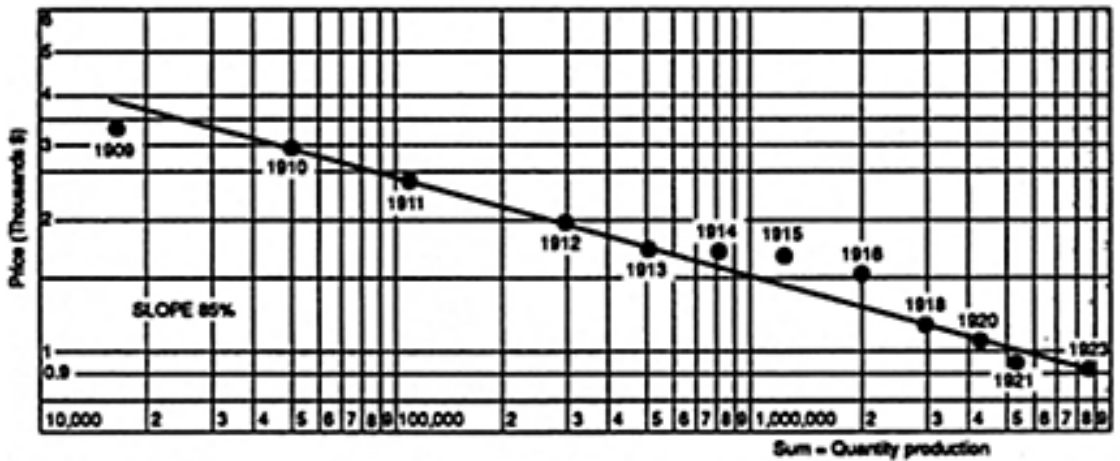

Every time production doublos, the price drops about $25 \%$.

B. Ford $=$ Model " $T$ " to Model "A"

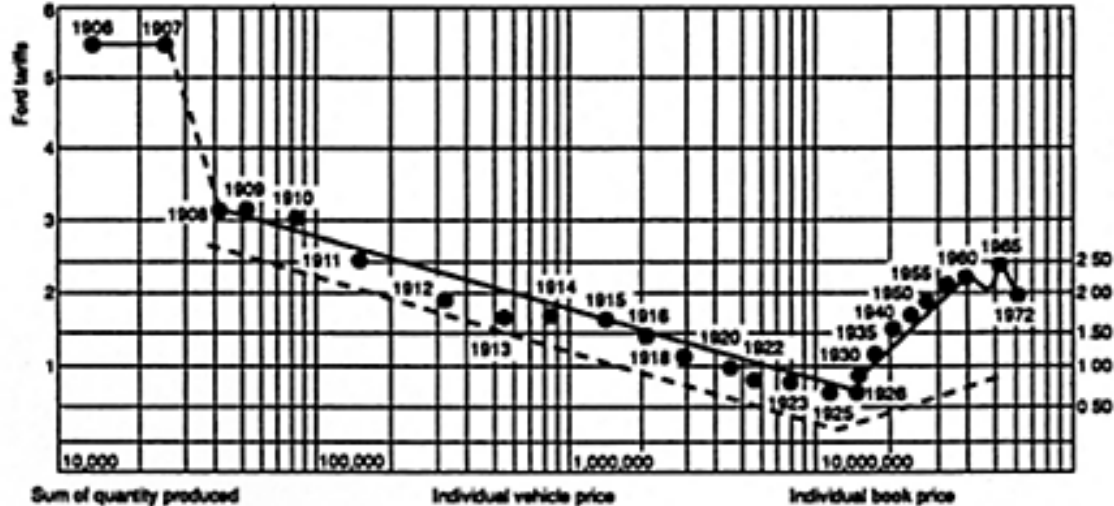

After a steady drop because of Model T's, the prices rise atter the introduction of new products.

\section{Advantages of productive flexibility (styllzed fact)}

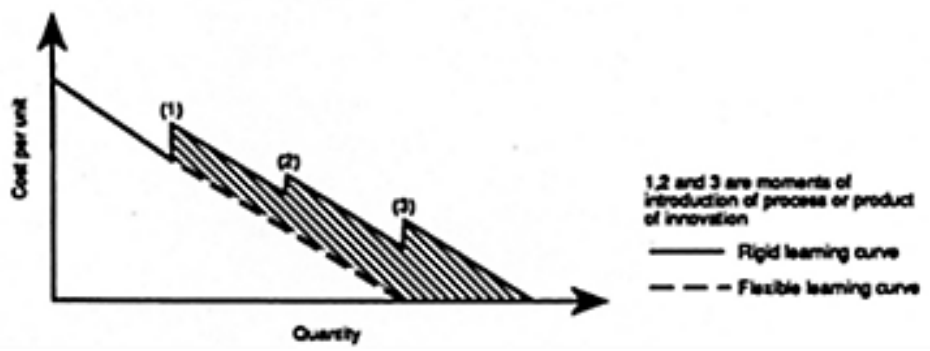

Figure 6.6 Learning and experience curves 
But, these strategies also require some "permissive" conditions and reach definite limits. As in the preceding case, these limits are traced by a set of characteristics belonging on one hand to the product life-cycles, and on the other to the dimensions of the markets. As regards the former, the product must be in a phase of "development," having been introduced with success onto the market. Once the product has been introduced and adjusted to consumer tastes, large enterprises can enter into the game, with long-term strategies and policies of experience curves to lower prices, and take large shares of potential markets.

Another condition is that the market for the product must be a growing one, or at least a more or less guaranteed mass market (for illustrations one can refer to the market of PCs, compact disks, etc).

In such interrelated conditions of both "product life-cyle" and "extension of the market," it is possible to combine the benefits of economies of scope and economies of scale in successful strategies, without leaving any significant space for medium-sized enterprises using only the benefits of economies of scope.

Of course many different variants of these two basic strategies can be imagined. In Figure 6.5 four basic strategies are illustrated.

\section{THE TRANSITION FROM FORDISM TO POST-FORDISM: CONCLUDING REMARKS}

The whole Fordist mode of production is in a course of great modification. It is too soon to try to formulate any reasonable predictions as regards the stable forms and configurations of the future industrial organization considered as a whole.

It seems, however, possible to conclude by focusing on certain crucial illustrates the new form and principles of the post-Fordist age). points and issues of the present process of transition (see Figure 6.7 which

\section{Quality versus quantity: the new content of the norms of production}

If we consider the new norms of production, it is increasingly evident that, in most situations, it is no longer sufficient to produce at low cost (through long series, economies of scope, and so on). Differentiation and quality must now enter into the productive process. According to the new tastes of consumers, and their volatility, or to different international standards (both technical and cultural), maintaining a position in the market necessarily means built-in capacity of the sort that allows the productive process to follow the many, largely unpredictable changes. New constraints of quality and differentiation are now combining with the traditional constraints of producing in long series and at low costs. In my view, this is the reason why just-in-time techniques are so important, and so successfully used by the 


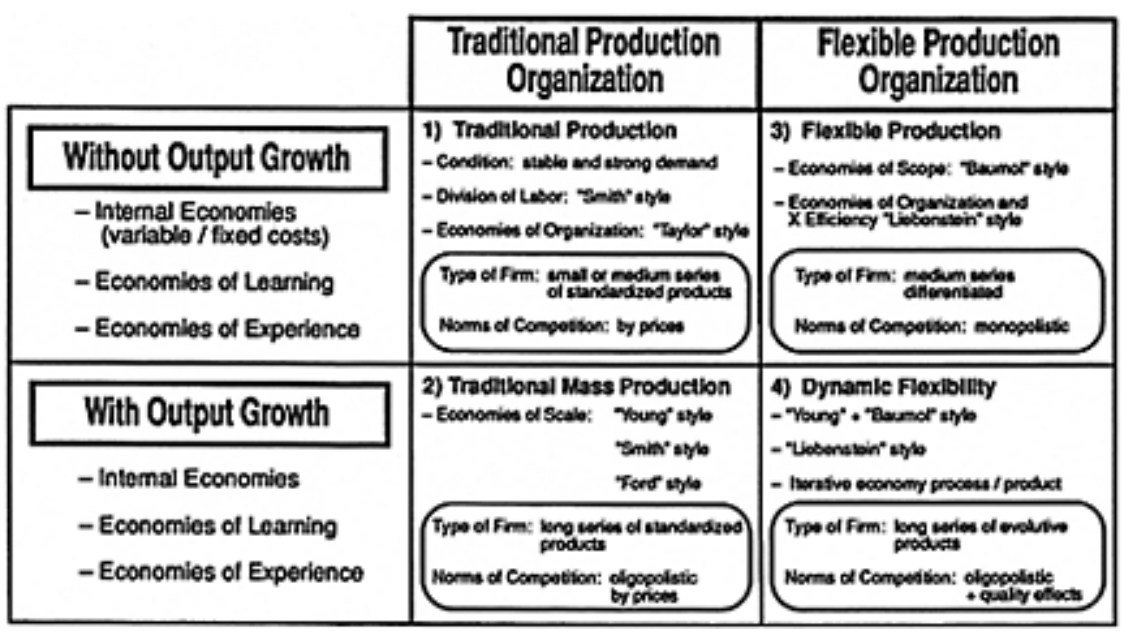

Figure 6.7 Origin of productivity gains and form of competition: a typology

Japanese firms. Far beyond the economies in "circulating capital" (stocks, in-flow products, etc.) the key to success must be attributed to the concept of production through flexible (or modulable) work standards, first introduced into the production lines by Ohno inside the Toyota Motor Company. Along with the new production norm, a new model of work organization based on high investments in human resources is emerging (Coriat 1990).

\section{Price versus nonprice competitiveness: the sophistication of the norms of competition}

As far as norms of competition are concerned, this means a parallel modification; nonprice competitiveness as opposed to strictly cost competitiveness is becoming more and more important. This is a direct consequence of the growing role played by the constraints of product differentiation and quality, arising from the structurally unstable markets. But, as I have tried to show, the growing importance of nonprice competitiveness must also be related to the opportunities created by new technical tools and organizational concepts. Since many different strategies can be pursued by firms, new ways are being found to bypass the rough and very rigid requirements of pure costcompetitiveness. Flexible specialization practices, or strategies of dynamic flexibility, open certain opportunities to create profitable niches or segment the market. Thus the firms using these new opportunities can conceive strategies based on principles of nonprice competitiveness. More generally, flexibility revitalizes forms of "Chamberlinian" competition even inside the classical oligopolistic forms of economic rivalry. The whole competitive game is turning out to be much more complex and refined than it used to be. 


\section{Is a new post-Fordist "virtuous circle" of growth conceivable?}

Based on all these new principles and arrangements, a large variety of models can be imagined. But it is clear that all the virtual possible macro-arrangements are not equally stable and efficient. I have elsewhere identified three basic - more or less sustainablemodels of post-Fordism. (Coriat 1990).

To conclude this chapter, I have chosen to focus on one of those three alternative models. The central point of this model is that it is constructed on the basis of a possible new "virtuous circle," which embodies and assumes all the novelties and characteristics of the post-Fordist age, as regards the set of interrelated norms emerging from the new general environment.

As shown in Figure 6.8 this model rests on two related pillars: quality and product differentiation on one side, quality of the organization and of worker qualifications on the other. One must note that there is a strong reciprocal link between the two pillars, in the sense that:

a) high and continued investment in organization and human resources is the strategic basis established to face the competition through differentiation and quality,

b) high quality and adequate differentiation policy as regards market changes allows firms to capture some monopolistic rents on the market, even in very competitive environments.

Thus, qualifications nurture quality and quality nurtures qualifications. This "qualification-quality" model is supported by a specific "engine of growth" (see Figure 6.8 , and for concrete example of such a model one may refer to some of the German and Swedish strategies; for the German case, see Streeck 1988). According to market conditions, this model uses, either separately or together, the benefits of flexible specialization and of dynamic flexibility strategies. Thus the different new principles of the efficiency associated with the rise of the post-Fordist economy (e.g. the Marshall, Baumol, and Arrow effects) can be pursued in a cumulative way.

In my own vision of the current transformations of the capitalist economy, there is only a very slight probability that this model will become a reality. 


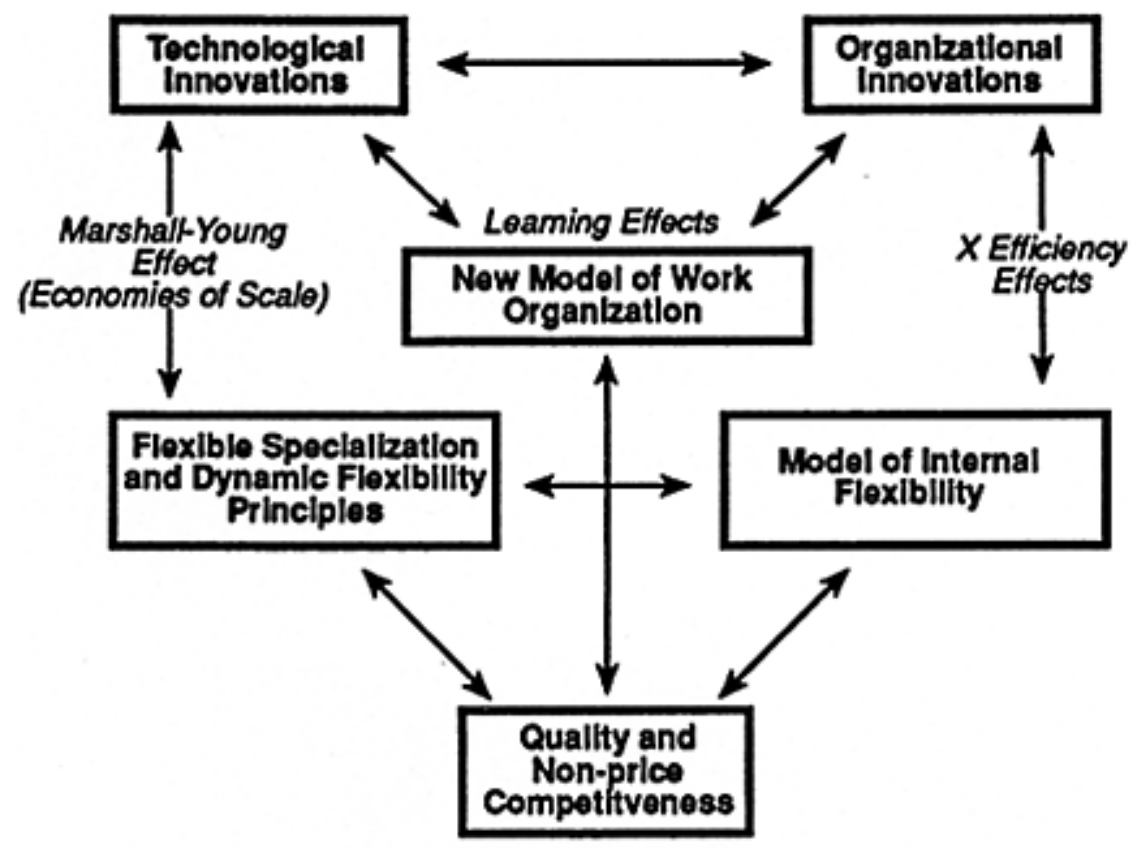

Figure 6.8 The quality skills model

But no-one can contest the right to dream built into the constitution of human beings; and as is obvious, the German car makers such as Mercedes or BMW have found a very profitable way of making dreams come true. 